\title{
The effectiveness of a model-based health education program on protective behavior against human papillomavirus in female drug abusers: a randomized controlled trial
}

\author{
Maryam Shokoohi ${ }^{1}$, Mansoureh Jamshidimanesh ${ }^{1}$, Hadi Ranjbar ${ }^{1}$, Mohsen Saffari ${ }^{2}$, Afrooz Motamed ${ }^{3}$ \\ ${ }^{1}$ Iran University of Medical Science, Iran \\ ${ }^{2}$ Baqiyatallah University of Medical Sciences, Iran \\ ${ }^{3}$ Mehrad Hospital, Iran
}

\begin{abstract}
Introduction: Human papillomavirus (HPV) is one of the most prevalent sexually transmitted infections (STI), which can cause cancer and genital warts. Drug abuse is associated with an increased risk of STIs, and drug users have poor awareness of HPV. This study aimed to examine the effect of an educational program based on the health belief model (HBM) on promoting protective behaviors among female drug abusers.

Material and methods: This study was a randomized controlled trial. Eighty eligible female drug abusers from ten drop-in centers located in Tehran were included in the study using convenience sampling. Randomization was applied at the center level, and all centers were divided into intervention and control centers. Data were collected using a self-administered questionnaire at four stages (before intervention, immediately, one month, and three months after intervention). Data were analyzed using repeated measures ANOVA test.

Results: The model-based health education program had a significant effect on perceived susceptibility, perceived severity, perceived benefits, cues to action, and self-efficacy scores $(p<0.001)$. The scores of perceived barriers did not change significantly $(p>0.05)$.
\end{abstract}

Conclusions: The educational program based on HBM had a positive effect on the subjects' beliefs regarding HPV protective behaviors, but it was not significantly effective on reducing perceived barriers.

HIV AIDS Rev 2020; 19, 1: 16-23

DOI:

Key words: education, human papillomavirus, drug abusers, health belief model, public health.

\section{Introduction}

Human papillomavirus (HPV) is the most common sexually transmitted infection (STI) as well as the most common cause of cervical cancer and genital warts. It is a predisposing factor for the malignancies of vagina, vulva, penis,

Address for correspondence: Mansoureh Jamshidimanesh, Midwifery Department, Iran University of Medical Science, School of Nursing \& Midwifery, Rashid Yasemi Str., 1996713883, Tehran, Iran, e-mail: jamshidmanesh2018@gmail.com anus, rectum, and oropharynx [1]. Also, it is responsible for the financial burden of these diseases [2]. A meta-analysis of studies published between 1995 and 2009, which studied one million women with normal cytology, estimated that the prevalence of global HPV was around $11.7 \%$ [3]. The prevalence of HPV infection in Iran was estimated to be
Article history:

Received: 18.04.2019

Received in revised form: 14.07.2019

Accepted: 15.07.2019

Available online: 10.10 .2019
International Journal of HIV-Related Problems

HIV \& AIDS

R e vi e w 
$79.3 \%$ of cancer patients and $7 \%$ of general female population [4]. Despite the role of HPV in etiology of severe health problems, the evidence showed that different populations have not enough information about the virus $[5,6]$.

High-risk sexual behaviors such as unprotected vaginal, anal, or oral sex and having multiple sexual partners are among the risk factors for HPV infection [7]. Drug abuse is a strong predictor of high-risk sexual behaviors [8], and the prevalence of HPV in female drug addicts is considerably high [9]. This high prevalence is related to having multiple sexual partners, unprotected sex, and trading sex for money or drugs, which are more common among female drug addicts $[10,11]$. Moreover, the possibility of screening for cervical cancer is lower in female drug abusers, while there is a strong association between drug abuse and the risk of cervical intraepithelial neoplasia [12].

While the prevalence of synthetic drugs abuse in women and young people has increased in Iran, the intention to receive healthcare is very low due to addiction-related stigma [13]. Therefore, preventative interventions such as an increase in level of general knowledge about HPV and an improvement in the use of protective methods for HPV infection in this group of vulnerable women are especially important.

One of the most used models of education on preventing sexual risk behaviors, increase screening behaviors, and vaccination is the health belief model (HBM). This model has several basic structures, which aim to predict why are people engaged in preventive behaviors, why are they looking for a screening, and how they control their diseases [14]. There are several studies on the effect of HBM on papillomavirus vaccination $[15,16]$, condom use [17], and cervical cancer screening $[18,19]$. As far as we are aware, the HBM has not been tested in the context of sexual behaviors in drug abusers. The current study was conducted to determine the effectiveness of a health education program based on the HBM on HPV protective behaviors in female drug abusers in Iran.

\section{Material and methods}

\section{Design and sample}

This randomized controlled study was conducted in ten drop-in centers in Tehran, Iran, between February and July 2017. The centers were randomly assigned into two groups: control and intervention. The randomization was conducted by a research assistant who was not familiar with the centers. The reason for randomization at center level was the prevention of information about contamination between subjects in intervention and control groups. Samples have entered the groups using convenience sampling. The interim analysis was performed with 33 participants in each group. Because there were significant differences between the scores of two groups, no more subjects were included into the study.

The inclusion criteria were: 18 years of age or older, being sexually active, ability to read and write, and absence of warts in the genital and anal areas. The exclusion criterion was being absent for more than one session of the educational program.

Subjects in the intervention group received three onehour training sessions education based on HBM in three weeks. The control group received general information about sexually transmitted infections, which was routinely presented in the centers. All participants completed the study questionnaire at baseline, immediately after the intervention, one month, and three months after the intervention.

\section{Intervention}

The content of the first session was about genital anatomy and HPV transmission routs. The subject of the second session was related to health problems associated with HPV, prevention methods, genital warts, and treatments. The second session aimed to increase perceived sensitivity and severity. The third session presented the effects of benefits, barriers, and self-efficacy, and its content was about cervical cancer screening, condom use and negotiating, information about HPV vaccinations, and the places where women can receive free healthcare.

At the end of each session, the opportunity to ask questions and discuss the matter was provided to the study subjects. To provide cues to action during the follow-up period, a pamphlet and phoneline consultation were offered. The pamphlet consisted of six pages of summary information about HPV was given after the intervention in order to study the information. At the end of the three-month follow-up, the same educational program was provided for subjects in the control group (Figure 1).

\section{Measures}

We used a two-part questionnaire for data gathering. The first part was a demographic data questionnaire, and included age, level of education, age at first sexual relationship and type of sex, condom use, screening for cervical cancer and sexually transmitted diseases, information about HPV and HPV vaccine, and number of sexual partners.

The second part was a researcher-designed questionnaire based on HBM. The study team designed the questionnaire to evaluate the efficacy of the intervention. The process of questionnaire design consisted of four steps including developing an item pool, receiving expert opinions about items, determining the impact score of each item, and psychometric evaluation of the questionnaire. Psychometric evaluation included the face and content validity, and the determination of reliability.

In the first step, the research team developed an initial item pool. The items in the pool were obtained from a comprehensive literature review that included the Center for Disease Control (CDC) website, the UpToDate website, and gynecology textbooks. In the second step, items were discussed in a panel of experts, which included infectious disease specialists, health education experts, and gynecolo- 


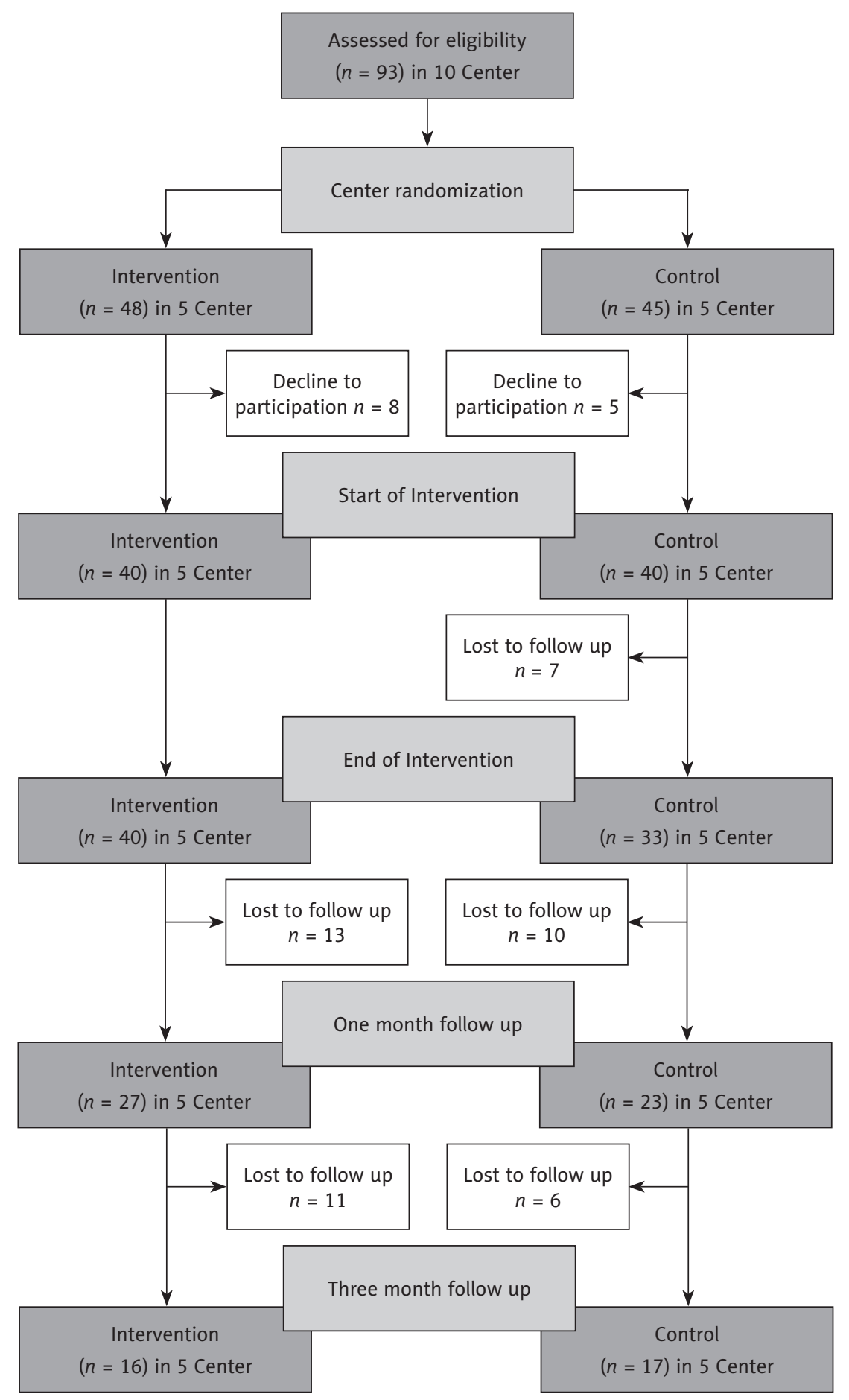

Figure 1. The consort diagram of sample recruitment

gist. Then, the items were sent to 15 experts to determine the impact score of each item. They were asked to score each item based on the importance of being in the questionnaire from 1 (extremely not essential) to 5 (extremely essential). The items with an impact score higher than 1.5 remained in the questionnaire.
The face and content validity was determined by using an agreement of 10 experts in the field of infectious disease, health education, and gynecology, and five people from the study population. At the end of this steps, 33 items remained in the questionnaire. For construct validity of the questionnaire, exploratory factor analysis (EFA) 
was performed. To analyze the data through EFA, a Kyser-Miralcan (KMO) sampling test was used. This index is variable between zero and one, and it is used to determine whether the obtained correlation matrix has a significant difference. Based on this, the factor analysis was accepted and Bartlett's test was used. After calculating the correlation matrix among the variables, factor extraction was performed. In this study, an eigenvalue of more than 0.5 was used to determine the number of factors producing the questionnaire.

The reliability of the questionnaire was determined by test re-test method and calculation of internal consistency. In the test re-test method, 15 subjects from the study popu- lation completed the scale twice with 20 days interval. Then, the Pearson correlation coefficient was calculated $(r=0.87)$. The data from 150 subjects from study population was used in the calculation of internal consistency $(\alpha=0.86)$.

There were seven items in perceived susceptibility (beliefs regarding the chance of getting or being at risk of HPV), eight items in perceived severity (beliefs regarding the consequences and sequelae of acquiring HPV), four items in perceived benefits (beliefs regarding the advantages), and three items in perceived barriers (costs or obstacles of advised actions). The items in these constructs were scored on a five-point Likert scale (from 0: strongly disagree to 4: strongly agree). There were three items in the cues to action

Table 1. Demographic characteristics of the respondents

\begin{tabular}{|c|c|c|c|}
\hline Factor & $\begin{array}{c}\text { Intervention } \\
n=40\end{array}$ & $\begin{array}{l}\text { Control } \\
n=40\end{array}$ & $p$ value \\
\hline Age (years), mean (SD) & $32.35(7.07)$ & $33.27(6.59)$ & $\mathrm{t}=1.64, \mathrm{df}=3, p=0.654$ \\
\hline \multicolumn{4}{|l|}{ Education } \\
\hline Primary education & $4(10)$ & $8(20)$ & \multirow{4}{*}{$\chi^{2}=2.55, \mathrm{df}=3, p=0.466$} \\
\hline Guidance school & $12(30)$ & $11(27.5)$ & \\
\hline High school & $15(37.5)$ & $16(40)$ & \\
\hline University education & $9(22.5)$ & $5(12.5)$ & \\
\hline Age of first sex (years), mean (SD) & $17.537(5.29)$ & $16.97(3.81)$ & $\mathrm{t}=1.36, \mathrm{df}=2, p=0.504$ \\
\hline \multicolumn{4}{|l|}{ Type of sex } \\
\hline Vaginal sex & $23(57.5)$ & $20(50)$ & \multirow{4}{*}{$\chi^{2}=1.209, \mathrm{df}=3, p=0.751$} \\
\hline Vaginal, oral sex & $4(10)$ & $4(10)$ & \\
\hline Vaginal, anal sex & $3(7.5)$ & $6(15)$ & \\
\hline Vaginal, anal, oral sex & $10(25)$ & $10(25)$ & \\
\hline \multicolumn{4}{|l|}{ Condom use } \\
\hline Never & $30(75)$ & $24(60)$ & \multirow{4}{*}{$\chi^{2}=4.00, \mathrm{df}=3, p=0.26$} \\
\hline Seldom & 7 (17.5) & $7(17.5)$ & \\
\hline Sometimes & $1(2.5)$ & $5(12.5)$ & \\
\hline Always & $2(5)$ & $4(10)$ & \\
\hline \multicolumn{4}{|l|}{ Screen for cervical cancer } \\
\hline Yes & $18(45)$ & $17(42.5)$ & \multirow{2}{*}{$\chi^{2}=0.051, \mathrm{df}=1, p=0.822$} \\
\hline No & $22(55)$ & $23(57.5)$ & \\
\hline \multicolumn{4}{|l|}{ Screen for sexually transmitted disease } \\
\hline Yes & $13(32.5)$ & $17(42.5)$ & \multirow{2}{*}{$\chi^{2}=0.853, \mathrm{df}=1, p=0.356$} \\
\hline No & $27(67.5)$ & $23(57.5)$ & \\
\hline \multicolumn{4}{|l|}{ Heard about HPV/HPV vaccine } \\
\hline Yes & $3(7.5)$ & $7(17.5)$ & \multirow{2}{*}{$\chi^{2}=1.82, \mathrm{df}=1, p=0.17$} \\
\hline No & $37(92.5)$ & $33(82.5)$ & \\
\hline \multicolumn{4}{|l|}{ Number of sex partners } \\
\hline 1 & $28(70)$ & $26(65)$ & \multirow{4}{*}{$\chi^{2}=1.077, \mathrm{df}=4, p=0.898$} \\
\hline 2 & $6(15)$ & $6(15)$ & \\
\hline 3 & $5(12.5)$ & $5(12.5)$ & \\
\hline 4 and more & $1(2.5)$ & $3(7.5)$ & \\
\hline
\end{tabular}


construct (strategies used as reminders for advised behaviors), and eight items in self efficacy (confidence regarding the ability to do the advised action). These two constructs were scored on a five-point Likert scale (from 0: never, to 4: always).

The Iran University of Medical Sciences' ethics committee approved the study protocol (IR.IUMS.REC.1395.29385). We registered the study in the Iranian Registry of Clinical Trials (IRCTID: IRCT2016121131346N1). All subjects were informed of the aims and methods of the study, and all participants have signed an inform consent form.

\section{Statistical analysis}

SPSS (version 16) was used to analyze the data. Independent t-test was used to compare the scores between the two groups. A repeated measures ANOVA was applied to com- pare the effectiveness of intervention between two groups. Multiple linear regression was used to evaluate the interaction between self-efficacy and the other constructs of the HBM.

\section{Results}

The characteristics of the study subjects in both groups are presented in Table 1. No significant differences were observed between the two groups regarding demographic variables.

Table 2 shows the mean scores for the HBM constructs for both groups. No significant differences between the intervention and control groups at the baseline regarding the HBM constructs were found. All of the HBM constructs scores improved significantly in the intervention group, except perceived barriers $(p=0.45)$.

Table 2. Mean (SD) of HBM constructs measures at baseline (T0), immediately (T1), and at 1-month (T2) and 3 months (T3); results of repeated measure analyses variance in both studied groups. Intervention (I); Control (C)

\begin{tabular}{|c|c|c|c|c|c|}
\hline Structures of HBM & $\begin{array}{c}\text { T0 } \\
\text { Mean (SD) }\end{array}$ & $\begin{array}{c}\text { T1 } \\
\text { Mean (SD) }\end{array}$ & $\begin{array}{c}\text { T2 } \\
\text { Mean (SD) }\end{array}$ & $\begin{array}{c}\text { T3 } \\
\text { Mean (SD) }\end{array}$ & \multirow{2}{*}{$\begin{array}{l}\text { Repeated } \\
\text { measure }\end{array}$} \\
\hline Number of samples & $\begin{array}{l}\text { I }(n=40) \\
\text { C }(n=40)\end{array}$ & $\begin{array}{l}\text { I }(n=40) \\
\text { C }(n=33)\end{array}$ & $\begin{array}{l}\text { I }(n=27) \\
\text { C }(n=23)\end{array}$ & $\begin{array}{l}\text { I }(n=16) \\
\text { C }(n=17)\end{array}$ & \\
\hline \multicolumn{6}{|c|}{ Perceived susceptibility (score) } \\
\hline Intervention & $2.35 \pm 0.50$ & $3.11 \pm 0.36$ & $3.56 \pm 0.36$ & $3.39 \pm 0.34$ & $<0.001$ \\
\hline Control & $2.56 \pm 0.79$ & $2.58 \pm 0.69$ & $2.77 \pm 0.71$ & $2.84 \pm 0.64$ & 0.009 \\
\hline$t$-test & 0.159 & $<0.001$ & $<0.001$ & 0.005 & $0.009^{\circledR}$ \\
\hline \multicolumn{6}{|c|}{ Perceived severity (score) } \\
\hline Intervention & $2.15 \pm 0.51$ & $3.45 \pm 0.38$ & $3.50 \pm 0.35$ & $3.41 \pm 0.31$ & $<0.001$ \\
\hline Control & $2.20 \pm 0.70$ & $2.25 \pm 0.74$ & $2.51 \pm 0.74$ & $2.61 \pm 0.52$ & 0.03 \\
\hline$t$-test & 0.703 & $<0.001$ & $<0.001$ & $<0.001$ & $<0.001^{\circledR}$ \\
\hline \multicolumn{6}{|c|}{ Perceived benefits (score) } \\
\hline Intervention & $2.43 \pm 0.61$ & $3.58 \pm 0.43$ & $3.51 \pm 0.49$ & $3.59 \pm 0.37$ & $<0.001$ \\
\hline Control & $2.62 \pm 0.67$ & $2.57 \pm 0.60$ & $2.81 \pm 0.59$ & $2.92 \pm 0.52$ & 0.82 \\
\hline$t$-test & 0.184 & $<0.001$ & $<0.001$ & $<0.001$ & $0.005^{\circledR}$ \\
\hline \multicolumn{6}{|c|}{ Perceived barriers (score) } \\
\hline Intervention & $1.69 \pm 0.49$ & $1.93 \pm 0.77$ & $1.81 \pm 0.93$ & $2.02 \pm 0.98$ & 0.45 \\
\hline Control & $1.57 \pm 0.87$ & $1.57 \pm 0.87$ & $1.47 \pm 0.69$ & $1.35 \pm 0.73$ & 0.76 \\
\hline$t$-test & 0.466 & 0.069 & 0.163 & 0.034 & $0.022^{\circledast}$ \\
\hline \multicolumn{6}{|l|}{ Cues to actin (score) } \\
\hline Intervention & $1.28 \pm 1.08$ & $3.54 \pm 0.54$ & $3.69 \pm 0.48$ & $3.79 \pm 0.31$ & $<0.001$ \\
\hline Control & $1.74 \pm 1.23$ & $1.45 \pm 1.18$ & $2.23 \pm 1.24$ & $2.49 \pm 0.92$ & $<0.001$ \\
\hline$t$-test & 0.07 & $<0.001$ & $<0.001$ & $<0.001$ & $0.023^{\circledR}$ \\
\hline \multicolumn{6}{|l|}{ Self-efficacy (score) } \\
\hline Intervention & $1.54 \pm 0.92$ & $3.65 \pm 0.41$ & $3.81 \pm 0.17$ & $3.30 \pm 0.14$ & $<0.001$ \\
\hline Control & $1.99 \pm 1.42$ & $1.62 \pm 0.91$ & $1.83 \pm 0.95$ & $1.67 \pm 0.82$ & 0.16 \\
\hline$t$-test & 0.480 & $<0.001$ & $<0.001$ & $<0.001$ & $<0.001^{\circledast}$ \\
\hline
\end{tabular}


Table 3. Regression table: the effect of changes in construct scores on self-efficacy construct

\begin{tabular}{l|c|c|c|c|c}
\hline & B & SE B & $\boldsymbol{\beta}$ & $\boldsymbol{t}$ & $p$ \\
\hline Perceived susceptibility & 0.27 & 0.32 & 0.10 & 0.85 & 0.397 \\
\hline Perceived severity & 0.04 & 0.29 & 0.02 & 0.13 & 0.895 \\
\hline Perceived benefits & -0.21 & 0.20 & -0.12 & -1.06 & 0.291 \\
\hline Perceived barriers & -0.35 & 0.16 & -0.16 & -2.20 & 0.031 \\
\hline Cues to action & 0.49 & 0.13 & 0.53 & 3.77 & $<0.001$ \\
\hline
\end{tabular}

The results of the linear regression are shown in Table 3. Cues to action score had the strongest positive effect on self-efficacy scores. Perceived barriers score had the strongest negative effect on self-efficacy scores.

\section{Discussion}

The results of the current study showed that an HBMbased educational program could improve the knowledge and beliefs of women regarding HPV prevention. The follow-up assessments revealed that scores of perceived susceptibility, severity and benefits, and cues to action increased in the intervention group. This was one of the first studies to examine the HBM-based intervention among female drug addicts, with the aim to improve protective behavior against HPV. Previous studies on HPV have examined the effect of interventions on vaccinations and Pap smears, and the use of condoms was completed separately and on other populations $[15,19]$. However, the self-efficacy assemble in the current study consisted of multiple precautionary measures, including condom use, vaccinations, and Pap smears.

Our results are in line with previous studies findings. The results of a study on college students in Sweden indicated that an increase in perceived susceptibility and perceived severity could lead to an increase in papillomavirus vaccination and condom use [15]. Moreover, the college students who agreed to have the papillomavirus vaccination had higher scores in perceived severity, susceptibility, and benefits $[20,21]$. Other studies have also found that increased perceived severity [22] and increased perceived benefits [16] were associated with subjects with papillomavirus vaccinations.

Similarly, a study investigating men and women in South Africa found a positive correlation between perceived severity and susceptibility and condom use [23]. Karimi also found that an improvement in scores of perceived susceptibility, severity, benefit, and cues to action for male drug users in Iran preceded to an increase in condom use, an increased tendency for HIV testing, and a decrease in high-risk sexual relationships [24]. A meta-analysis also showed a positive impact of improved perceived benefit scores on the likelihood of engaging in protective behaviors [25]. The results of a previous study showed that an increase in perceived benefits was positively related to the intention of obtaining the papillomavirus vaccination, which was in line with our findings [16].

In the present study, the change in scores of cues to action was higher than other constructs of the HBM. This result is consistent with previous studies, which showed that cues to action had a positive effect on screening behaviors. For example, the results of one study found that reminders are effective in the increasing mammography adherence [26]. This HBM construct is also considered to have the highest positive impact on the emergence of positive health behaviors, e.g. Pap smears [27].

The intervention failed to decrease the perceived barriers scores in the intervention group. Perceived barriers referred to the obstacles to the regular and accurate use of condoms, having Pap smears, and HPV vaccination. The use of a condom is influenced by several factors, including drug abuse [28] and the disagreement of sexual partners [29]. Lack of access to female condoms was also a barrier to the current intervention. Previous studies have indicated that there was a relationship between taking Pap smears and perceived susceptibility, severity, Benefits, barriers, and self-Efficacy [19, 30].

In contrast, however, one study found that there was no significant relationship between perceived susceptibility, severity, barriers, and benefits and having Pap smears, and that the most critical factor was laziness [31]. Similarly, another study concluded that recommendations by healthcare providers were the only effective encouragement for undergoing Pap smears [32].

The decrease in self-efficacy, however, along with the increase in perceived barriers in the follow-up phase could indicate the importance of interventions on the commitment to undertake healthier behaviors. We can also presume that the low efficiency of perceived barriers to precautionary behaviors was the result of factors mentioned above - the lack of recommendations by healthcare providers.

Another factor that stops from HPV vaccination was its high price and the fact that health insurance companies in Iran do not cover the vaccine. The results of previous studies have shown that health insurance coverage can positively affect HPV vaccination [33]. Therefore, we believe that including the HPV vaccination in the national immunization program in high-risk populations as well as including it in insurance coverage would have a positive effect on the perceived barriers construct. 
Our results demonstrate a positive effect of self-efficacy on subjects' protective behaviors. However, unlike other parts of the questionnaire, self-efficacy scores decreased slightly during follow-up sessions, which may have influenced the effectiveness of the intervention. We assume that this decrease was the result of an escalation in perceived barriers scores, based on the results of linear regression. The results of previous studies have shown that the failure to overcome perceived barriers could have an adverse effect on safe sex behaviors [34, 35].

A cross-sectional study on African-American US immigrants found that self-efficacy was one of the essential predictors of condom use [36]. Some other studies have also found that self-efficacy was the strongest predictor of safe sexual behaviors, such as using condoms and having diagnostic sexual disease tests $[37,38]$, and that it had a positive effect on other safe sexual behaviors [39].

In our study, after educational sessions, pamphlets were given to the subjects, so they could refer to them for HPV information, and the follow-up phone consultations also helped to enhance the effects of the intervention. These strategies may be the reason for the sustainability of the mean scores of the constructs. The results of previous studies have shown that follow-up measures could increase the likelihood of undertaking healthier behaviors [40].

At the end of follow-ups in the control group, there were significant differences in scores of perceived susceptibility, perceived severity, and cues to act. It is more likely that there were media or other educational programs involved, which provided additional information apart from educational intervention in this study group. Participants of the control group has become curious about the matters and were pursuing answers, which could increase their scores in these constructs over time. That caused significant differences in the control group, but more important was that the education in present study had more effect comparing with other programs. Therefore, the intervention group had more significant differences over the control group.

The current study had several limitations. The self-report questionnaires were the main data collection tool, which may have affected the accuracy of reported behaviors. Also, in Iran, speaking about sexual relationships and dangerous behaviors are considered a taboo. Therefore, the subjects may have been more likely to report desirable behaviors and omit unfavorable ones. To overcome this limitation, aims of the study were discussed with the participants, and they were assured of their confidentiality. Since the subjects stayed in camps and drop-in centers for a long time and did not have contact with the community during the three months of follow-up, finding out about their use of condom or a screening test evaluation was not possible.

\section{Conclusions}

This study shows that an educational program based on the HBM can affect addicted women's health beliefs and that it can influence their self-efficacy regarding HPV protective behaviors. As this study did not affect the subjects' perceived barriers scores, future studies are encouraged to determine what the perceived barriers are and take the required measures to reduce them. Similar interventions could be conducted on males with a history of drug abuse and other high-risk groups such as prisoners. In the context of health, the measurement of actual behaviors is almost impossible. Therefore, self-efficacy is considered to be the most powerful indicator of real behavior. The increase in self-efficacy in the current study indicates the effectiveness of an HBM-based intervention on female drug abusers' HPV preventive behaviors.

\section{Acknowledgements}

We would like to express our gratitude to the director and staff of drop-in centers and all study participants for their cooperation.

\section{Conflict of interest}

The authors declare no potential conflicts of interest with respect to the research, authorship, and/or publication of this article.

\section{References}

1. CDC. The Link Between HPV and Cancer 2016. Available at: https:// www.cdc.gov/hpv/parents/cancer.html.

2. De Vuyst H, Alemany L, Lacey C, et al. The burden of human papillomavirus infections and related diseases in sub-saharan Africa. Vaccine 2013; 31 Suppl 5: F32-46.

3. Bruni L, Diaz M, Castellsagué M, Ferrer E, Bosch FX, de Sanjosé S. Cervical human papillomavirus prevalence in 5 continents: metaanalysis of 1 million women with normal cytological findings. J Infect Dis 2010; 202: 1789-1799.

4. Khorasanizadeh F, Hassanloo J, Khaksar N, et al. Epidemiology of cervical cancer and human papilloma virus infection among Iranian women - analyses of national data and systematic review of the literature. Gynecol Oncol 2013; 128: 277-281.

5. Barras V, Jacot-Guillarmod M. Human papillomavirus: what do young people really know about it? Revue Medicale Suisse 2014; 10: 1297-1301.

6. Kwang NB, Yee CM, Shan LP, Teik CK, Chandralega KN, Abdul Kadir A. Knowledge, perception and attitude towards human papillomavirus among pre-university students in Malaysia. Asian Pac J Cancer Prev 2014; 15: 9117-9123.

7. CDC. Genital HPV Infection - Fact Sheet: Center for Disease Control and Prevention; 2017. Available at: https://www.cdc.gov/std/ hpv/stdfact-hpv.htm.

8. Shorey RC, Fite PJ, Choi H, Cohen JR, Stuart GL, Temple JR. Dating violence and substance use as longitudinal predictors of adolescents' risky sexual behavior. Prev Sci 2015; 16: 853-861.

9. Ghosh I, Ghosh P, Bharti AC, Mandal R, Biswas J, Basu P. Prevalence of human papillomavirus and co-existent sexually transmitted infections among female sex workers, men having sex with men and injectable drug abusers from eastern India. Asian Pac J Cancer Prev 2012; 13: 799-802.

10. Berhan Y, Hailu D, Alano A. Polysubstance use and its linkage with risky sexual behavior in university students: significance for policy makers and parents. Ethiop Med J 2013; 51: 13-23.

11. Stahlman S, Javanbakht M, Stirland A, Guerry S, Gorbach PM. Methamphetamine use among women attending sexually transmitted 
disease clinics in Los Angeles County. Sex Transm Dis 2013; 40: 632-638.

12. Kricker A, Burns L, Goumas C, Armstrong BK. Cervical screening, high-grade squamous lesions, and cervical cancer in illicit drug users. Cancer Causes Control 2013; 24: 1449-1457.

13. Nikfarjam A, Shokoohi M, Shahesmaeili A, et al. National population size estimation of illicit drug users through the network scale-up method in 2013 in Iran. Int J Drug Policy 2016; 31: 147-152.

14. Glanz K, Rimer BK, Viswanath K. Health behavior and health education: theory, research, and practice. John Wiley \& Sons, 2008.

15. Grandahl M, Rosenblad A, Stenhammar C, et al. School-based intervention for the prevention of HPV among adolescents: a cluster randomised controlled study. BMJ Open 2016; 6: e009875.

16. Schaefer Ziemer K, Hoffman MA. Beliefs and attitudes regarding human papillomavirus vaccination among college-age women. J Health Psychol 2013; 18: 1360-1370.

17. Katikiro E, Njau B. Motivating factors and psychosocial barriers to condom use among out-of-school youths in Dar es Salaam, Tanzania: a cross sectional survey using the health belief model. ISRN AIDS 2012; 2012: 170739.

18. Lambert CC, Chandler R, McMillan S, Kromrey J, Johnson-Mallard V, Kurtyka D. Pap test adherence, cervical cancer perceptions, and HPV knowledge among HIV-infected women in a community health setting. J Assoc Nurses AIDS Care 2015; 26: 271-280.

19. Parsa P, Sharifi F, Shobeiri F, Karami M. Effects of group counseling based on health belief model on cervical cancer screening beliefs and performance of rural women in Kaboudrahang, Iran. Asian Pac J Cancer Prev 2017; 18: 1525-1530.

20. Barnard M, George P, Perryman ML, Wolff LA. Human papillomavirus (HPV) vaccine knowledge, attitudes, and uptake in college students: implications from the Precaution Adoption Process Model. PLoS One 2017; 12: e0182266.

21. Guvenc G, Seven M, Akyuz A. Health belief model scale for human papilloma virus and its vaccination: adaptation and psychometric testing. J Pediatr Adolesc Gynecol 2016; 29: 252-258.

22. Christy SM, Winger JG, Raffanello EW, Halpern LF, Danoff-Burg S, Mosher CE. The role of anticipated regret and health beliefs in HPV vaccination intentions among young adults. J Behav Med 2016; 39: 429-440.

23. Hounton SH, Carabin H, Henderson NJ. Towards an understanding of barriers to condom use in rural Benin using the Health Belief Model: a cross sectional survey. BMC Public Health 2005; 5: 8.

24. Karimy M, Abedi A, Amin-Shokravi F, Tavafian SS. Preventing HIV transmission among the opiate-dependent population in $\mathrm{Za}$ randieh: evaluation of the HBM-based educational programs. Health Education \& Health Promotion 2013; 1: 21-31.

25. Carpenter CJ. A meta-analysis of the effectiveness of health belief model variables in predicting behavior. Health Commun 2010; 25: 661-669.

26. Saywell RM, Champion VL, Zollinger TW, et al. The cost effectiveness of 5 interventions to increase mammography adherence in a managed care population. Am J Manag Care 2003; 9: 33-44.

27. Moore de Peralta A, Holaday B, Hadoto IM. Cues to cervical cancer screening among US Hispanic women. Hisp Health Care Int 2017; 15: 5-12.

28. Deuba K, Kohlbrenner V, Koirala S, Ekström AM; CAT-S group. Condom use behaviour among people living with HIV: a seven-country community-based participatory research in the Asia-Pacific region. Sex Transm Infect 2018; 94: 200-205.

29. Donta B, Begum S, Naik DD. Acceptability of male condom: an Indian scenario. Indian J Med Res 2014; 140 Suppl: S152-156.

30. Kocaöz S, Özçelik H, Talas MS, et al. The effect of education on the early diagnosis of breast and cervix cancer on the women's attitudes and behaviors regarding participating in screening programs. J Cancer Educ 2018; 33: 821-832.
31. McFarland DM. Associations of demographic variables and the Health Belief Model constructs with Pap smear screening among urban women in Botswana. Int J Womens Health 2013; 5: 709-716.

32. Acharya Pandey R, Karmacharya E. Cervical cancer screening behavior and associated factors among women of Ugrachandi Nala, Kavre, Nepal. Eur J Med Res 2017; 22: 32.

33. Kessels SJ, Marshall HS, Watson M, Braunack-Mayer AJ, Reuzel R, Tooher RL. Factors associated with HPV vaccine uptake in teenage girls: a systematic review. Vaccine 2012; 30: 3546-3556.

34. Volk JE, Koopman C. Factors associated with condom use in Kenya: a test of the health belief model. AIDS Educ Prev 2001; 13: 495-508.

35. Winfield EB, Whaley AL. A comprehensive test of the Health Belief Model in the prediction of condom use among African American college students. Journal of Black Psychology 2002; 28: 330-346.

36. Asare M, Sharma M, Bernard AL, Rojas-Guyler L, Wang LL. Using the health belief model to determine safer sexual behavior among African immigrants. Journal of Health Care for the Poor and Underserved 2013; 24: 120-134.

37. Lin P, Simoni JM, Zemon V. The health belief model, sexual behaviors, and HIV risk among Taiwanese immigrants. AIDS Educ Prev 2005; 17: 469-483.

38. Zak-Place J, Stern M. Health belief factors and dispositional optimism as predictors of STD and HIV preventive behavior. J Am Coll Health 2004; 52: 229-236.

39. Li X, Lei Y, Wang H, He G, Williams AB. The Health Belief Model: a qualitative study to understand high-risk sexual behavior in Chinese men who have sex with men. J Assoc Nurses AIDS Care 2016; 27: 66-76.

40. Shahnazi H, Sabooteh S, Sharifirad G, Mirkarimi K, Hassanzadeh A. The impact of education intervention on the Health Belief Model constructs regarding anxiety of nulliparous pregnant women. J Educ Health Promot 2015; 4: 27. 